the known chemistry of mixed ligand chelate formation, as we describe elsewhere $^{5}$, the choice of suitable combinations is straightforward. For example, Martell et al. ${ }^{6}$ demonstrated, using potentiometric titrations, that Th(IV) formed very stable mixed ligand chelates with EDTA, salicylate and catechol $\left(10^{11}-10^{13}\right.$ times more stable than EDTA alone). As expected, $\mathrm{Pu}(\mathrm{IV})$ reacted similarly.

We reject the suggestion, unsupported by experimental evidence, that alternative explanations besides mixed ligand complexes are responsible for our results. Our experiments ${ }^{4,5}$, including ultrafiltration, solvent extraction, and in vivo reversal of salicylate antipyresis by $\mathrm{Zn}$ and $\mathrm{Cu}$ EDTA, provided experimental evidence for mixed ligand chelate formation. The proposed mixed ligand chelate of $\mathrm{Pu}$ with DTPA and salicylate is depicted by the following structure:

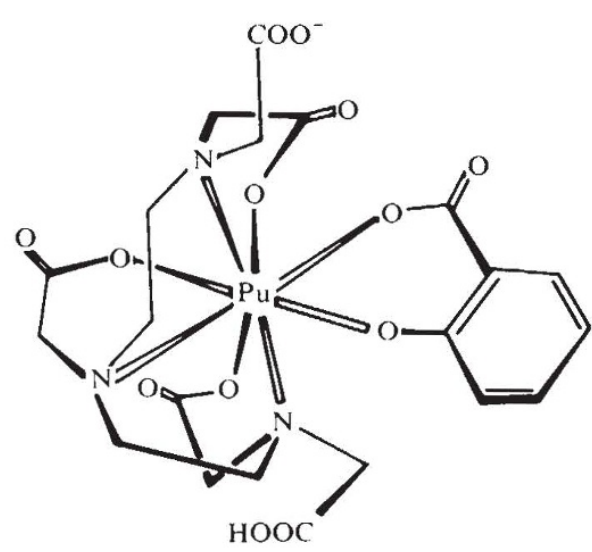

The requirements for biological transport emphasised by May and Williams have long been known. It is not necessarily true, however, that highly charged polyaminopolycarboxylic acids are confined to extracellular spaces. A very small but adequate fraction of these chelants penetrate intracellular space as shown by sustained excretion of metals following single treatment ${ }^{7.8}$. Charged metal ions, for example, chromate, can also penetrate cell membranes and reach cell interiors ${ }^{9}$. May and Williams' proposal that synergistic chelation therapy occurs when one drug mobilises the metal and the other traps it in plasma is inapplicable to our systems, as compounds such as salicylate and catechol by themselves do not react with $\mathrm{Pu}(\mathrm{IV})$ in in vivo conditions.

Although computer simulation studies of speciation in biological fluids have a certain value, they are unnecessary in our therapeutic investigations, as even simple non-computer calculations readily show that the very strong mixed ligand chelates used by us bind $>99 \%$ of the total metal. Indeed, this is shown in their own calculations ${ }^{10}$, even with single chelants, and computer calculations used previously ${ }^{11}$ by one of us. The ability of complexing agents to bind metals in the blood stream does not necessarily coincide with the ability to remove metals deposited in the tissues $^{12}$.

\section{JACK SCHUBERT}

\section{S. KROGH DERR}

Hope College,

Holland, Michigan 49423

1. Schubert, J. A. Rev. nucl. Sci. 5, 369-412 (1955)

2. Magos, L. \& Stoytchev, T. Br. J. Pharmac. 35, 121-126 (1969).

3. Volf, V. Hith Phys. 29, 61-68 (1975).

4. Schubert, J. \& Derr, S. K. Nature 275, 311-313 (1978).

5. Schubert, J. \& Derr, S. K. Radiat. Res. (in the press).

6. Carey, G. H., Bogucki, R. F. \& Martell, A. E. Inorg. Chem 3, 1288-1295 (1964).

7. Fried, J. F., Graul, E. H., Schubert, J. \& Westfalt, W. M Atompraxis 5, 1-5 (1959).

8. Lindenbaum, A. \& Schubert, J. Nature 187, 575-576 (1960).

9. Mertz, W. Physiol. Rev. 49, 163-239 (1969)

10. May, P. M. \& Wiltiams, D. R. FEBS Lett. 78, 134-138 (1977).

11. Sharma, V. S. \& Schubert, J. J. Am. chem. Soc. 91, 6291-6296 (1969)

12. Schubert, J. \& Rosenthal, M. W. Am. med. Ass. Archs ind. Hith 19, 169-178 (1959).

\section{Evolution of the $3^{\prime}, 5^{\prime}$ internucleotide bond}

DHINGRA AND SARMA ${ }^{1}$ posed the question "Why do nucleic acids have 3',5' phosphodiester bonds?". They concluded from a detailed NMR investigation of the conformations of dinucleoside monophosphates that $2^{\prime}, 5^{\prime}$-linked oligomers are unlikely to form helical structures that are stabilised by base-stacking. Thus $2^{\prime}, 5^{\prime}$ linked nucleic acids would be less suitable for participation in present day biochemical operations that involve helix formation. Dhingra and Sarma considered a polymer as a set of repeating dimer structures and did not consider the perturbations that could be introduced by the presence of a complementary strand. There is, of course, evidence that $2^{\prime}, 5^{\prime}$ linked oligomers can complex with $3^{\prime}, 5^{\prime}$ linked complementary polymers, although the melting temperatures of these complexes do tend to be lower than in the case of an all $3^{\prime}, 5^{\prime}$-linked complex ${ }^{2}$.

We considered this same question some years ago, and predicted ${ }^{3}$ that the $2^{\prime}, 5^{\prime}$ bond in a helical oligonucleotide would be more susceptible to non-enzymatic chain breakage than would the $3^{\prime}, 5^{\prime}$ bond. A large difference in kinetic stability was subsequently demonstrated experimentally for a triple helix of oligoadenylates and poly $U$ in mildly basic solution ${ }^{4}$. Thus during the early chemical evolution of nucleic acids, it seems reasonable to suppose that there was a strong selective pressure for the $3^{\prime}, 5^{\prime}$ bond, and against the $2^{\prime}, 5^{\prime}$ bond.

\section{A. USHER}

Department of Chemistry,

Cornell University,

Ithaca, New York 14853
1. Dhingra, M. M. \& Sarma, R. H. Nature 272, 798 (1978).

2. Michelson, A. M. \& Monny, C. Biochim. biophys. Acta 149, 107 (1967).

3. Usher, D. A. Nature new Biol. 235, 207 (1972).

4. Usher, D. A. \& McHale, A. H. Proc. natn. Acad. Sci. U.S.A. 73, 1149 (1976)

5. Usher, D. A. Science 196, 311 (1977).

SARMA AND DHINGRA REPLY-Since the publication of our paper in Nature we have carried out extensive NMR studies in $100 \%$ water on self-complementary $2^{\prime} 5^{\prime}$ dinucleoside monophosphates, that is

$$
2\left(2^{\prime} 5^{\prime} \mathrm{CpG}\right) \rightleftharpoons \begin{aligned}
& \frac{2^{\prime} 5^{\prime} \mathrm{CpG}}{\mathrm{GpC} 22^{\prime} 5^{\prime}} \\
& .
\end{aligned}
$$

to monitor the Watson-Crick hydrogen bonding protons. The data showed that 2 '5'-linked dimers have little proclivity to form Watson-Crick hydrogen bonded miniature double helices under conditions in which their $3^{\prime} 5^{\prime}$ analogues have been shown ${ }^{1}$ to form such complexes. The study has revealed that the availability of a complementary dimer does not introduce enough perturbations to the intrinsic stereochemistry of $2^{\prime} 5^{\prime}$ systems to induce the formation of minature double helices. In this connection, it is important to note that in the reported crystal structure of $2^{\prime} 5^{\prime} \mathrm{ApU}$ no miniature double helices have been observed ${ }^{2}$, contrary to the crystal structure findings on $3^{\prime} 5^{\prime} \mathrm{ApU}$ and $3^{\prime} 5^{\prime} \mathrm{GpC}^{3-8}$, but like 3'5' $\mathrm{UpA}^{9}$.

\section{R. H. SARMA \\ M. M. DHINGRA}

Institute of Biomolecular Stereodynamics and Department of Chemistry,

State University of

New York at Albany

Albany, New York 12222

1. Krugh, T. R., Laing, J. W. \& Young, M. A. Biochemistry 15, 1224-1228 (1976)

2. Shefter, E., Barlow, M., Sparks, R. A. \& Trueblood, K. N Acta crystallogr. B25, 895-909 (1969).

3. Rosenberg, J. M. et al. Nature 243, 150-154 (1973).

4. Rosenberg, J. M., Seeman, N. C., Day, R. O. \& Rich, A. $J$. molec. biol. 104, 145-167 (1976).

5. Seeman, N. C. et al. J. molec. Biol. 104, 109-144 (1976).

6. Hingerty, B. et al. Biopolymers 14, 227-236 (1975),

7. Day, R. O., Seeman, N. C., Rosenberg, J. M. \& Rich, A Proc. natn. Acad. Sci. U.S.A. 70, 849-853 (1973).

8. Hingerty, B. et al. Acta Cryst. B32, 2998-3013 (1976).

9. Seeman, N. C., Sussman, J. L., Berman, H. M. \& Kim, S. H. Nature non. Biol. 233, 90-92 (1971).

\section{Matters Arising}

Matters Arising is meant as a vehicle for comment and discussion about papers that appear in Nature. The originator of a Matters Arising contribution should initially send his manuscript to the author of the original paper and both parties should, wherever possible, agree on what is to be submitted. Neither contribution nor reply (if one is necessary) should be longer than 300 words and the briefest of replies, to the effect that a point is taken, should be considered. 